\title{
Grounding Aesthetic Preference in the Bodily Conditions of Meaning Constitution
}

\author{
Towards an Enactive Approach
}

Alfonsina Scarinzi

\begin{abstract}
A Bstr ACт Mark Johnson's work The Meaning of the Body presents John Dewey's pragmatism and pragmatist aesthetics as the forerunners of the antiCartesian embodied enactive approach to human experience and meaning. He rejects the Kantian noncognitive character of aesthetics and emphasizes that aesthetics is the study of the human capacity to experience the bodily conditions of meaning constitution that grows from our bodily conditions of life. Using Mark Johnson's view as a starting-point, this paper offers the beginning of an enactive approach to aesthetic preference contributing to bringing human aesthetic behavior research closer to the enactive approach to human experience. Following enactive studies on bodily sense-making and embodied emotions, I identify the bodily conditions of meaning constitution in which aesthetic preference is grounded with the subject's self-regulatory visceral embodied constitution of viable degrees of value of the environmental factors according to her bodily structure. Unlike mainstream aesthetic preference research in empirical aesthetics, I claim that the subject's aesthetic preference constitution requires the lived experience of the bodily conditions of meaning constitution through the conscious experience of the subjectively aroused lived body. The implausibility of the mind/body dichotomy of current aesthetic preference research is highlighted.

KEYWORDS Pragmatist aesthetics, enactivism, Mark Johnson, John Dewey, embodiment, lived body, phenomenology
\end{abstract}

\section{Introduction}

Because of its alleged noncognitive character, nothing connected with the aesthetic can have any role in meaning, conceptualization and reasoning! ${ }^{1}$

In his work The Meaning of the Body Mark Johnson comments with these words on the reasons for the devaluation of aesthetics in mainstream Anglo-American analytical philosophy and philosophy of language. These two strands of philosophy consider aesthetics as not being part of meaning proper because the aesthetic dimension of experience and thought is neither conceptual nor propositional. Johnson points out that the influential aesthetic theory of Immanuel Kant has also contributed to relegate aesthetics to a secondary and devaluated status in philosophy and science. Kant adopts the mind-body dualism of Enlightenment faculty psychology, in which feeling as bodily occurrence is contrasted with thought as intellectual cognitive process, and reduces aesthetics to feeling alone considered to be nonconceptual and incapable of giving rise to knowledge. ${ }^{2}$ 
In his work, Johnson rejects the noncognitive view of aesthetics and the Cartesian mind/body dichotomy that underlies it. Drawing upon John Dewey's pragmatist aesthetics and his "somatic naturalism", ${ }^{3}$ he claims that aesthetics is the study of everything that goes into the human capacity to make and experience the bodily pre-linguistic cognitive, emotional and sensory-perceptual conditions of meaning constitution having its origins in the organic activities of living creatures and in their organismenvironment transactions. ${ }^{4}$ It underlies linguistic meaning, which is parasitic on it. Following Dewey, Johnson points out that the paradigmatic case of these pre-linguistic bodily conditions of meaning constitution is meaning-making in art. They culminate in aesthetic experience, which is not sharply marked off from other experiences. According to Dewey, an aesthetic experience is the integration of all the elements of ordinary experience that gives the experience a larger feeling of wholeness in the interactive flow of organism-environment transactions. ${ }^{5}$ The continuity of aesthetic experience with normal processes of living modifies and sharpens our perception and communication. As Richard Shusterman, in his analysis of Dewey's work Art as Experience, puts it, drawing an analogy between Dewey and Merleau-Ponty, the expressive perceptual role of the lived body is amplified in aesthetic experience, even if Dewey himself does not use this phenomenological notion. ${ }^{6}$

In his work, Johnson brings pragmatism and consequently also the pragmatist view of aesthetics closer to the rising enactive mind thesis or enactivism. ${ }^{7}$ Enactivism conciliates phenomenology and cognitive science, acknowledging that especially the phenomenological studies on the lived body can clarify and guide scientific research on subjectivity and consciousness. ${ }^{8}$ The enactive mind thesis rejects the Cartesian mind/ body dichotomy and emphasizes the anti-representationalist view that the mind is embodied and distributed over body, brain and environment. Accordingly, cognition depends on the individuals' bodily possibilities of action and sensorimotor skills. The backdrop against which action and cognition in the environment as well as experience take place is the pre-reflective dimension of the perceptual and cognitive-emotional lived body. ${ }^{9}$ In enactivism living beings are considered to be autonomous and active agents. They follow laws set up by their own activity (autopoiesis). The organism-environment transactions are possible thanks to the agent's coupling with the environment in a relation of co-determination. By such a coupling, agents actively generate their identity by selecting from the environment their viable world, called "cognitive domain", that is brought forth or enacted by that agent's autonomous mode of cou- 
pling with the environment. In the process of bringing forth the cognitive domain self-regulatory preferences and hence bodily viable degrees of values of environmental factors in the interactive flow of organismenvironment transactions are constituted..$^{10}$

The truly embodied enactive nature of aesthetics, which Johnson acknowledges in his reevaluation of the field, has been marginalized by mainstream human aesthetic behavior research. As the field of aesthetic preference research shows, it has adopted the disembodied dualistic approach of classical cognitive science for studying the sensory-perceptual bodily character of aesthetics. ${ }^{11}$ In mainstream research on human aesthetic behavior the notion of aesthetic preference is defined as the subject's choice to focus her selective attention on certain features of everyday objects or of works of art in their sensory perception which leads to positive emotions and aesthetic pleasure. ${ }^{12}$ This can be induced by perceptions that do not arouse strong emotions such as a sunset, a painting, a car, an elegant mathematical proof, or a piece of music, as Martindale and Moore point out. ${ }^{13}$ An aesthetic preference may be expressed in a propositional form in the following way: I like $X$ or I prefer $Y$.

The aim of this article is to begin developing an enactive approach to aesthetic preference, contributing in this way to do justice to the truly embodied enactive nature of aesthetics. I will discuss the enactive bodily mediated perceptual and cognitive-emotional ground of aesthetic preference; I will not deal with its linguistic propositional form. I contend that aesthetic preference constitution as a vehicle of aesthetic pleasure requires the lived experience of the bodily conditions of embodied meaning constitution through the conscious experiential access to the subjectively lived body. I argue that 'the aesthetic' of an aesthetic preference is characterized by a feeling of wholeness which is similar to the one that according to Dewey characterizes an aesthetic experience. I argue that its emergence can be experienced through the cognitive-emotional evaluation of the aroused lived body.

In what follows, I first propose an overview of the existing models in aesthetic preference research, putting into focus the implausibility of their dualistic disembodied approach and proposing to recast the research questions of the aesthetic preference research field in enactive terms. I then turn to the enactive approach and develop the idea that against the background of the enactive approach to the bodily conditions of meaning constitution, aesthetic preference can be grounded in the subject's embodied visceral viable degrees of value of the environmental factors she encounters in the organism-environment transactions. 
Finally, I emphasize the role of the embodied enactive interdependence of cognition and emotion ${ }^{14}$ in the bodily mediated experience of 'the aesthetic' as a felt pleasurable quality of an aesthetic preference.

\section{An Overview of the Dualistic Disembodied Models in Aesthetic Preference Research and their Implausibility}

Aesthetic preference research has become a field of inquiry especially of empirical aesthetics and psychology of aesthetics. The arousal-based model or preference-for-novelty model by Daniel Berlyne, the preferencefor-prototype-model by Colin Martindale and Kathleen Moore and the MAYA-model by Paul Hekkert and colleagues, which postulates a preference for neither too novel nor too prototypical stimuli, are well-known. The stubborn focalization of the research field on the properties of environmental stimuli as predictive factors of aesthetic preference that intrinsically motivate people to seek and to process information is also well-known. It has led the field to reduce aesthetic preference research to the never ending and sterile debate on whether novelty or prototypicality or a balance between them determines human aesthetic preference. In spite of their lack of potential for the future development of aesthetic preference research and human aesthetic behavior, in what follows I will illustrate the mentioned models with the purpose of emphasizing the implausibility of their dualistic disembodied theoretical basis. This has not been tackled in the literature so far. Discussing the dualistic implausibility of the mentioned models is necessary now, for developing an enactive approach to aesthetic preference requires recasting the theoretical premises of the research field. In this section I will put into focus the pragmatist implausibility of the existing models. Also their phenomenological implausibility will be highlighted, for phenomenology is a constitutive part of enactivism and the development of an enactive approach to aesthetic preference within Johnson's project of reevaluation of aesthetics requires coping with two phenomenological issues: the lived body and lived experience, even if Johnson in his work does not take the road of phenomenology in spite of its relevant role in enactivism.

To my mind, the most limiting shortcoming of the dualistic existing models for investigating aesthetic preference is the lack of attention to the process of how mind and body, cognition and emotion, make contact in aesthetic preference constitution. While all three models take the subject's bodily sensory-perception of stimulus features into account, the question of its relation with emotion ${ }^{15}$ and cognition, as well as the relation between emotion and cognition, is tackled in a partial and un- 
satisfactory way or it is not tackled at all. This prevents the field from studying aesthetic preference as part of the flow of human experience in the subject's active interaction with the environment. It reduces aesthetic preference research to the observation of stimulus-response dynamics, neglecting the fact that the subject's action and behavior are the first cause of all exposure to stimuli and that the subject and the environment are in a relation of co-determination, as Merleau-Ponty observes in The Structure of Behaviour, ${ }^{16}$ and as also enactive research indicates.

\section{Berlyne's Disembodied Model}

The arousal-based model by Berlyne ${ }^{17}$ inspired by behaviorism eliminates mind entirely. In line with behaviorism that considers the mind to be a black box and hence unapproachable, Berlyne neglects it and focuses on the lawful relation between input (stimuli) and behavior (outputs). His approach is akin to positivist objectivism in science and does not take the subjective experience of one's own body into account. For this reason it can be considered to be a disembodied model..$^{18}$ Berlyne hypothesizes that in the perception of an object, preference for any stimulus is determined by its arousal potential. Arousal is a bodily event. It is a general state of the organism that affects the organization of its behavior between one extreme, for example sleep, and the other extreme, for example disorganization. ${ }^{19}$ The relationship between preference and arousal potential is described by the Wundt curve: stimuli with medium arousal potential are most selected by human attention. As arousal potential increases to this medium level, preference increases from neutrality to maximal liking. Further increases in arousal potential leads to a decline in liking and to increasing degrees of displeasure. The arousal potential of a stimulus is determined by its psychophysical properties (physical qualities of the stimulus such as intensity, brightness, pitch), ecological properties (learned meaningfulness of a stimulus) and collative variable properties such as novelty, complexity and incongruity. Collative variables refer to the comparison of a stimulus with a prior expectation. With Berlyne's words: "the word 'collative' [...] adverts to the fact that, in order to decide how novel, surprising, complex, and so on, a pattern is, one must compare or collate information from two or more sources." ${ }^{20}$ The collative variables and the arousal potential are the two classes of concepts that are believed to allow us to make predictions about emotional responses. These are simply explained with reference to the broader hedonic effects of complexity and novelty and hence to their arousal potential. The problem with this view is that bodily arousal 
is undifferentiated and cannot support any specific emotion. In order to acquire emotional specificity, arousal has to be labeled through appraisal as a cognitive process of interpretation of bodily events. ${ }^{21}$ But Berlyne's approach lacks a theory of emotion that can account for the emotional specificity of arousal. The only thing that arousal in Berlyne's model allows to predict is enjoyment and aversion and hence simple positive and negative states as possible physical reactions, so that aesthetic preference remains a matter of the body alone.

\section{The Disembodied Model by Colin Martindale and Kathleen Moore}

The alternative to Berlyne's model is the preference-for-prototype model developed by Colin Martindale and Kathleen Moore and colleagues. ${ }^{22}$ They prefer to focus on the role of cognition, while arousal and appraisal that constitute emotion are eliminated completely. This model is disembodied because it does not take emotional bodily events into account. In line with the mind/body dichotomy, the authors cling to the view that feeling and emotions belonging to the body can overshadow cognition belonging to the higher faculty of the mind. Accordingly, the cognitive effects of any pleasurable stimulus that activates a mental representation would be completely overshadowed by emotions. Nevertheless, they do not leave aside the bodily excitatory nature of a stimulus. They propose the cognitive model of preference-for-prototype for explaining the cognitive patterns and consequences of aesthetic preference constitution as response to a perceptual stimulus.

According to the preference-for-prototype model, the most influent determinant or predictive factor of aesthetic preference is stimulus prototypicality. Aesthetic preference is determined by the extent to which a particular stimulus is typical of its class and is positively related to prototypicality because typical stimuli give rise to stronger activation of the salient cognitive categories and mental representations. The startingpoint of the preference-for-prototype model is the connectionist view of the mind. This is conceived as composed of interconnected cognitive units with different perceptual and conceptual tasks. Martindale and Moore point out that cognitive units are generally connected in a lateral inhibitory fashion. This means that the units coding more similar things are closer to one another and hence more able to inhibit one another. Lateral connections are not considered to be excitatory. This is a characteristic of vertical connections of cognitive units. A vertical connection is the connection between a cognitive unit and the superordinate category to which it belongs. For example, category exemplars are connected in 
an excitatory fashion with the cognitive unit coding the superordinate category to which they belong. Cognitive units differ in how activated they can become. Units coding more prototypical or more frequently encountered stimuli are stronger than those coding atypical or infrequent stimuli. According to Martindale and Moore, perception, cognition and aesthetic preference follow the same cognitive unit activation patterns. An example is the perception and recognition of a face. According to the authors, aesthetic preference induced by a face corresponds to the activation of exactly the same set of cognitive units devoted to face perception and recognition. The difference consists in the fact that while perception and recognition have to do with exactly which cognitive units are activated, aesthetic pleasure has to do with the net amount of activation of these units. As cognitive units coding prototypical stimuli are stronger or capable of greater activation, the stimuli that they code induce more pleasure. The authors do not go into the details of pleasure activation.

\section{The MAYA-Model: A Disembodied Compromise}

In aesthetic preference research Berlyne's model and the preference-forprototype model have given rise to the much discussed question of the ascendency of one model over the other. ${ }^{23}$ The MAYA-model has provided a solution. ${ }^{24}$ It has reconciled the above mentioned models with one another. Like the arousal-based model and the preference-for-prototype model, the MAYA- model does not tackle the question of how mind and body make contact in aesthetic preference constitution. Instead, the intrinsically motivating features of a stimulus are put into the foreground once more. The MAYA-model supports the position that both novelty and typicality ${ }^{25}$ will be positively related to aesthetic preference when the counteracting influence of these concomitant changes in the other variable is controlled for. The authors' studies show that people prefer novel objects as long as the novelty does not affect typicality. In other words, they prefer typicality given that this is not to the detriment of novelty.

From the point of view of empirical aesthetics, the empirical results of the study by Hekkert and colleagues are convincing. In striking a balance between novelty and typicality, in trying to be as innovative as possible, typicality must be preserved as much as possible. As the correlation between novelty and typicality falls short from being perfect, the unshared variance enables the independent manipulation of these variables. But even if Hekkert and colleagues find a solution to the problem of the ascendency of Berlyne's model and of the preference-for-prototype model over one another, they also reiterate once more the sterile reduction of 
aesthetic preference to the most intrinsically motivating properties of the perceptual stimulus.

\section{Recasting the Research Questions of the Aesthetic Preference}

\section{Research Field: Towards an Enactive Approach}

To my mind, the consequence of the focalization of the aesthetic preference research field on the stimulus features, and on the subjects' responses to them, has been the relegation of the subject to a passive role of obedience to the environment. From a pragmatist point of view such stimulus-centric approaches are implausible because they do not take into account the active engagement of the organism with its surroundings, which is also a phenomenological condition for perception and behavior. According to Dewey's view, which resonates with MerleauPonty's phenomenological view, the organism's encounters with the stimuli of the environment are possible only by her preceding activity and movement which are part of a process in which an organism seeks to survive and grow within different kinds of environments. The mind emerges as part of this activity. Hence mind and body, the higher and the lower, are in a relation of continuity with one another and with the environment. In pragmatist philosophy this is better known as Dewey's continuity principle. ${ }^{26}$ If we take the continuity principle into account, looking at aesthetic preference as a phenomenon that can be eviscerated from emotional bodily events or from the mind becomes implausible.

Also, in the three mentioned models, and in the studies conducted according to these models, the use of the third-person methodological approach that objectivizes the subject's response to a stimulus feature contributes to reiterating the phenomenological implausibility of these stimulus-centric approaches, for it leaves aside the study of the role of the subject's lived experience in aesthetic preference and the role of the subjectively lived body that allows the subject to have a conscious experiential access, both to her own implicit skill for movement and motor intentionality, and to the subjectively pre-reflective lived felt quality of a situation and of experience. ${ }^{27}$ Enactive research has shown that the firstperson approach allows the subject to have access to the lived experience of the felt quality of an experience and to its pre-conceptual, pre-reflective dimension that is cross-modal, as the same experiential patterns can appear in different sensorial modalities and convey the felt quality of an experience. $^{28}$

Reframing aesthetic preference research within Johnson's enactive reevaluation of aesthetics cannot leave aside the subject's pre-reflec- 
tive embodied dimension of meaning. What is crucial for the enactive reevaluation of aesthetics and for the development of an enactive approach to aesthetic preference is the fact that the pervasiveness of pre-linguistic embodied meaning at the corporeal level of experience is grounded in a non conscious pre-reflective dimension which the subjectively lived body is involved in. ${ }^{29}$ The lived body's unique status as a physical object, and as a backdrop against which actions and experiences in the world take place, becomes vividly apparent in the pre-reflective bodily self-consciousness: one's body shows itself to be a material thing animated from within by sensation and motility. Evan Thompson $^{30}$ gives the well-known example of a cup of hot tea. When I pick up a cup of hot tea, I feel the hot smooth surface of the porcelain and the heat penetrating my finger, and these sensations linger for a time after I have put the cup back down on the table. Such bodily experience is twofold: it is the experience of physical events that relate one's body to things and it is the experience of sensorial events that relate one's subjectively lived body to itself.

As Todres and Galvin ${ }^{31}$ following Eugène Gendlin point out, the conscious experience of the subjectively lived body is the subject's access to the pre-reflective dimension of experience. It is the access to a multisensorial pattern of feeling that is the basis for different felt qualities or felt sense of a situation and for the emergence of thought and understanding.

As Johnson points out, motor intentionality and the subjective experience of the feeling of qualities of an experienced situation, enable to account for meaning as grounded in bodily experience and hence also for aesthetics as visceral, pre-linguistic embodied meaning-making.

In this article I argue that the subject's conscious experiential access to her pre-reflective dimension of experience through her conscious experience of her subjectively lived body can allow her to become aware of the aesthetic as a felt pleasurable quality of an aesthetic preference. I shall return to this point in detail in the next section.

Against the background of enactivism, the pragmatist and phenomenological implausibility of current aesthetic preference research can be overcome only if the research questions of the field of aesthetic preference research are reformulated. Within the framework of Johnson's enactive reevaluation of aesthetics, it seems to me that the following research questions are promising for the future enactive development of the field: (1) how is aesthetic preference constituted in relation both to the human visceral bodily conditions of life and to the subject's sensorimotor activity in the environment?; (2) what is its function in the flow of 
organism-environment transaction?; (3) how can the subject have access to the nonconscious pre-reflective embodied meaning underlying 'the aesthetic' of aesthetic preference constitution?

In the following section I will not specifically and directly answer these questions. Rather, I will develop the first steps towards the beginning of an enactive approach to aesthetic preference constitution, starting by overcoming the pragmatist and phenomenological implausibility of current research on aesthetic preference. Instead of attempting at eviscerating aesthetic preference and its sensory-perceptual bodily character from cognition or from emotion and emotional bodily events, I will focus on how mind and body make contact in aesthetic preference constitution. I will propose to introduce the enactive embodied interconnection of cognition and emotion, and hence the continuity between mind and body, to aesthetic preference research.

\section{Grounding Aesthetic Preference in the Bodily Conditions of Meaning Con- stitution: an Enactive View}

My aim in this section is twofold. On the one hand, following enactive studies I will identify the process of the visceral conditions of aesthetic preference constitution with the process of the constitution of viable degrees of value the subject's lived body enacts or brings forth in the organism-environment transactions. I will put into the foreground especially the role of bodily sense-making. On the other hand, I will consider the lived body as a locus where mind and body, cognition and emotion, make contact both in aesthetic preference constitution and in the subjectively embodied experience of the aesthetic as a felt pleasurable quality of an aesthetic preference.

As Evan Thompson points out in his work Mind in Life, the lived body is a dynamic condition of the living body. ${ }^{32}$ One of the tasks of the enactive approach to human cognition is to understand a lived body as a special kind of autonomous system, whose sense-making brings forth or enacts a phenomenal world. ${ }^{33}$ In this section I will put into the foreground the way the enactive approach to aesthetic preference research can contribute to this task. In other words, I will put into the foreground how a subjectively lived body as a special kind of autonomous system and its sense-making, bring forth aesthetic preferences in the subject's enactment of her phenomenal world.

I will not tackle the methodological question of the first-person approach in enactivism mentioned in the previous section. 
Aesthetic Preference, Viable Degrees of Value and Bodily Sense-Making In the enactive literature the specific question of the process of aesthetic preference constitution and its embodied ground has not been discussed. Nevertheless, the enactive research has tackled the more general question of the visceral, self-regulatory preference constitution. ${ }^{34}$ Before dealing with the question of how the aesthetic of an aesthetic preference is experienced by the subject, I will discuss in the following the more general question of how the visceral ground of bodily mediated preferences is constituted. These can be considered to be the bodily and embodied nonconscious ground of aesthetic preference constitution brought forth by the lived body. I shall return to this point in details in the next subsection.

In order to better understand the enactive conceptual tools necessary to develop an enactive approach to aesthetic preference constitution at this point, I will make a digression and will explain two enactive notions which are essential to understand the visceral enactive dimension of the organic biological and embodied cognitive function of the subject's preference constitution and hence to make the first step towards an enactive approach in aesthetic preference research. The two notions are adaptivity and bodily sense-making.

Adaptivity is the subject's capacity to regulate herself with respect to the boundaries of her own structure and identity in the mutual and continuous exchanges with the environment. Adaptive processes permit the meaningful distinction of events that do not put the subject's organism directly in any danger. An example is the selection of more nutritive food that may be regulated by mechanisms that, with Di Paolo's words, "adaptively avoid the activation of more serious bio-energetic regulation (such as the consumption of reserves) which itself inherits a negative valence from its proximity to the boundary of viability". ${ }^{35}$ Such an adaptive selection has the function to preserve the subject's biological structure and identity and corresponds to the subject's own particular way of realizing and regulating autopoiesis. But this is not sufficient to constitute a visceral preference, for the notion of preference implies a process of bodily sense-making in the adaptive selection of environmental elements in the organism-environment transactions. ${ }^{36}$ The subject's embodied evaluation of the consequences of her interaction with the environment for the conservation of her identity, and for the expansion of her cognitive domain according to her identity and bodily structure, depends on the subject's constitution of viable degrees of value of adaptive selections. This determines an organismic preference constitution and is possible thanks to bodily sense-making. ${ }^{37}$

The core idea of bodily sense-making is that the whole organism is a 
vehicle of meaning which is dynamically constructed by the subject having a perspective on the world. In the interaction with and adaptation to the environment, bodily sense-making is the evaluation of an adaptation and takes place in the organism's coupling with the environment. It has both the function to contribute to maintaining the organismic integrity of the subject (regulation) and to expand the subject's cognitive domain through the active selection of viable environmental factors to be integrated into the subject's cognitive domain.

In the enactive literature the paradigmatic example of the constitution of degrees of value through adaptivity and bodily sense-making, and hence the paradigmatic example of organismic preference constitution, is the example of a bacterium swimming uphill in a sugar gradient as an organism capable of adaptivity and bodily sense-making. The sugar gradient becomes a space of possibilities for the organism that establishes different degrees of value and hence of self-regulatory visceral preference according to the viability of the environmental factor for the organism's bodily structure: concentration $\mathrm{x}$ of sugar is good, concentration $\mathrm{y}$ is better, concentration $\mathrm{z}$ not sufficient, etc. ${ }^{38}$

The constitution of different degrees of value is subordinated to the sensorimotor actions undertaken by the subject, in the case of the mentioned paradigmatic example the bacterium, in the environment (in the example above the action of the 'swimming uphill in a sugar gradient') and it is brought forth or enacted by the subject's autonomous mode of sensorimotor coupling with the environment. In this sense, it is the result of the so called enacted viability that occurs when the degree of value and hence the visceral self-regulatory preference constitution simply facilitate the continuing integrity and integration of the organism according to her sensorimotor coupling with the environment. The paradigmatic example of the bacterium mentioned above is a useful example to clarify this mechanism of enacted viability. For the bacterium, both the concentration $\mathrm{x}$ of sugar and the concentration $\mathrm{y}$ are viable degrees of value. But while concentration $\mathrm{x}$ of sugar is good, concentration $\mathrm{y}$ is better, which means that in the encounter with concentration $x$ the organism's bodily preference has a lower positive degree than the encounter with concentration y. In other words, both of them contribute in different ways to bodily self-regulation and to the extension of the organism's cognitive domain in enacting a phenomenal world.

As I have stressed above, the mentioned example is just a paradigmatic example. What is relevant for my concern here is the principle beyond the biological dynamics of an organism's adaptation. 
In developing the first step towards an enactive approach to aesthetic preference constitution, I interpret such a principle in a broader way and apply it to the dynamics of the pre-reflective embodied qualitative dimension, determining the bodily ground of an aesthetic preference constitution. I am making the point here that in my view, the selfregulatory organismic viable degrees of value represent the embodied backdrop of the felt qualitative dimension or felt quality of making the experience of and constituting an aesthetic preference in the organismenvironment transactions. In other words, such a backdrop represents the bodily condition grounded in the sense-making of the lived body which is necessary for constituting and feeling the qualities of an experienced aesthetic preference constitution. It corresponds to what Mark Johnson in his work considers to allow to account for aesthetics as visceral, pre-linguistic embodied meaning-making. In other words, it does justice to Dewey's continuity principle.

Even if as far as I know the notion of 'felt quality ${ }^{39}$ has never been used in connection to the visceral viable degrees of value and hence to bodily sense-making as bodily meaning constitution, I would like to use it in this contribution to better explain my point. As it will become clear in the following, I will propose that the use of 'felt quality' is a bit different from the one used by Mark Johnson in his The Meaning of the Body, for example, for Johnson focuses mainly on qualities of body motion, e.g. tension has a meaning grounded in felt muscular tension; linearity derives its meaning from directional qualities of bodily motion. ${ }^{40}$ In the case of preference constitution, motion alone is not enough, even if it is one of the conditions for preference constitution. Against the background of the enactive explanation of bodily sense-making and adaptation, both motion and the conscious and nonconscious embodied evaluation of embodied and environmental events, play a central role in identifying the felt quality of aesthetic preference constitution. Such a felt quality is determined by the embodied viable degrees of value of environmental factors, which are grounded in our bodily connections with things and are continuously in the making via our sensorimotor engagements and coupling with the environment. The meaning of the different degrees of value is known by the subject through the combination of the nonconscious evaluation of bodily sense-making and through the conscious evaluation of the quality of our different lived experiences in the interaction with the world. For example, $\mathrm{x}$ is good or $\mathrm{y}$ is better derive their meaning from a bodily degree of adaptation to environmental factors, which is prepared and developed in our nonconscious bodily 
self-regulatory activity and bodily sense-making, which is the source of their meaning, subordinated to movement, as the paradigmatic example of the bacterium has illustrated.

In an enactive approach to aesthetic preference constitution the nonconscious evaluative dimension mentioned above becomes the backdrop against which the evaluation of the qualitative dimension of our different encounters with different environmental factors is subjectively felt as a felt quality. In other words, the bodily sense-making of the lived body brings forth viable degrees of value, creating the visceral conditions for constituting and experiencing the felt quality of an enacted aesthetic preference in the phenomenal world.

I will argue in the following subsection that in the case of aesthetic preference constitution, the felt quality with an evaluative embodied function is the aesthetic of aesthetic preference, which emerges through the conscious experiential access to the lived body. This is the locus of contact of cognition and emotion in experiencing the aesthetic of aesthetic preference constitution.

The Role of the Lived Body and the Aesthetic of Aesthetic Preference as a Felt Pleasurable Quality

Enactive research on cognition, emotion and the lived body has emphasized that emotion and cognition, or also bodily sense-making and emotions, are embodied and interdependent. The point I will make in the following, is that the consequence of conceptualizing cognition and emotion as embodied and interdependent in an enactive approach to aesthetic preference is that a viable evaluation, such as a preference or an aesthetic preference, is cognitive-emotional, (it cannot be eviscerated from cognition or emotion) and that its viability is perceivable through the experiential access to the aroused lived body. ${ }^{41}$ In the following section, this idea will be developed in two interdependent steps. I will explain and use Giovanna Colombetti's enactive study on embodied emotion and sense-making ${ }^{42}$ and tie it to my conceptualization - inspired by John Dewey's aesthetic experience - of the aesthetic as a felt pleasurable quality of an aesthetic preference.

Colombetti has stressed that at the visceral level of preference generation not only the body plays a role in sense-making and hence in cognition, it is also inseparable from emotion, which is essential for the evaluation of viable environmental factors for the subject and hence for the constitution of self-regulatory preferences. According to Colombetti's enactive approach to emotion and bodily sense-making, bodily sense-making, which 
is central in the constitution of degrees of value and hence in preference constitution, manifests itself in the experience of the aroused lived body and hence in experience through embodied emotions such as fear, anger, happiness, guilt, anguish. These are the ways the subject evaluates bodily sense-making.

For my concern here it is relevant to keep in mind that the above mentioned embodied emotions are bodily mediated cognitive-emotional evaluations of the bodily sense-making of an adaptation to environmental factors the organism interacts with in the environment and of their viability. They allow to subjectively feel the cognitive-emotional qualitative dimension of the degree of value of our interaction with different environmental factors through the aroused lived body.

In developing the idea of the cognitive-emotional embodied evaluation, which the aroused lived body is a vehicle of, Giovanna Colombetti points out that, as there is no cognition without emotion and emotion is embodied, arousal needs no appraisal to be interpreted by the subject. The aroused body is immediately available as such to the subject's experience through the evaluation of the bodily aspects of emotion as part of the subject's evaluation of the experienced world. ${ }^{43}$ Bodily arousal subsumes the whole subject's organism's capacity to make sense of her world and is possible thanks to the lived body. Colombetti points out that in the same way as the pre-reflective lived body allows the experience of becoming aware of my body as that through which, for example, the experience of typing on the computer is possible, it allows to be similarly aware of the bodily arousal as that through which I am living the situation of an interview as anxiety provoking.

Against this background, we can say that in the process of the cognitive-emotional evaluation of and of adaptation to the environment, which are essential in bringing forth preferences and hence also aesthetic preferences, the central role of the lived body is twofold: (1) it is the pre-reflective backdrop against which the perceptual and motor experience is constituted, which is its classical role, traditionally studied in phenomenology; ${ }^{44}(2)$ it is the pre-reflective backdrop against which the cognitive-emotional evaluation of the experienced world takes place, which is its role in the enactive approach to emotion. ${ }^{45}$

With reference to the subjectively felt qualitative dimension of the degrees of value of different environmental factors, this means that this takes place against the backdrop of both a pre-reflective motor and cognitive-emotional lived body. Nevertheless, the cognitive-emotional, evaluative pre-reflective dimension of the aroused lived body is the distinctive 
backdrop against which a viable evaluation and hence a preference or aesthetic preference and the cognitive-emotional qualitative dimension of the degrees of value of different environmental factors are subjectively felt in the experience and perception of the world, which are subordinated to motion.

I believe that reevaluating aesthetic preference research in enactive terms requires focusing on the subject's conscious experiential access to the pre-reflective cognitive-emotional evaluation of viable degrees of value of environmental factors through the aroused lived body. I propose that through the access to this dimension the subject can become aware of a degree of felt viable - that is pleasurable - quality of an aesthetic preference as an emergent feeling of wholeness which I identify with 'the aesthetic' of an aesthetic preference. I consider it to be very similar to the feeling of wholeness characterizing an aesthetic experience according to John Dewey.

In the following I will clarify my point by taking into account John Dewey's notion of aesthetic experience and its constitutive dynamics and drawing an analogy between this and what I refer to as the 'aesthetic' of an aesthetic preference.

In his Art as Experience, John Dewey points out that aesthetic experience is possible in a world where suspance and crisis, disturbance and disorder, offer the opportunity for their resolution and hence the moment of passage from disturbance to harmony, which is the moment of intense life. According to Dewey, living the enjoyment of a period of harmony and hence an aesthetic experience is a temporary savored sense of culmination - a feeling of wholeness - because it is the beginning of a new relation to the environment that implies the disruption of the achieved equilibrium and hence a new tension between disorder or disruption and the search for a new harmony, which is the rhythm of organic life. ${ }^{46}$ With reference to Dewey's notion of aesthetic experience, Shusterman observes that an aesthetic experience has a living beauty "because its own sparkling career projects the process of its dying as it lives", as he formulates it. ${ }^{47}$

In my enactive approach to aesthetic preference constitution I propose that the same dynamics of the pleasurable passage from disturbance to harmony that enables the emergence of the feeling of wholeness and hence of a sense of culmination characterizing an aesthetic experience, can be applied to the emergence of the aesthetic as a pleasurable cognitiveemotional felt quality of an aesthetic preference. Against the background of enacted viability, such a quality may emerge from a similar dynamics, 
namely from the passage from an unviable degree of value, which corresponds to a situation that does not allow self-regulation and can be hence seen as a sort of disorder, to a viable one or also from a viable degree of value to a more viable one - the level of viability corresponding to a level of pleasurable degree of value. I believe that the conscious experience of the cognitive-emotional bodily conditions of this passage makes the experience of the felt qualitative dimension of the aesthetic as a bodily cognitive-emotional viable evaluation possible. It leads to the emergence of a feeling of wholeness. In my enactive approach, given the embodied and interdependent nature of emotion and cognition, the conscious bodily and bodily felt cognitive-emotional signal of the passage from $x$ is bad to $y$ is good and from $y$ is good to $z$ is excellent, for example, correspond to the passage from anxiety (low level of viability) to joy (high level of viability) or from joy (high level of viability) to happiness (higher level of viability) and hence to a situation of harmony or more harmony for the subject in the evaluation of the interaction with two or more different environmental factors. According to my enactive approach, the duration of the conscious cognitive-emotional bodily signal indicating the level of viability in the interaction with an environmental factor corresponds to the situation where the temporary feeling of wholeness as the bodily mediated experience of the felt pleasurable quality of an aesthetic preference, in other words 'the aesthetic', emerges.

Contrary to an aesthetic experience where the feeling of wholeness, according to Dewey, is temporary and optimal as the expression of an attained harmony, the feeling of wholeness and of pleasure related to the reflective experience of the cognitive-emotional bodily conditions of an aesthetic preference can be but temporary and relative. As it was stressed, it depends on the cognitive-emotional visceral degrees of value against which the experience of the feeling of wholeness of an aesthetic preference emerges and is subjectively felt.

In other words, the degree of pleasurable (viable) value of the experience of the aesthetic of an aesthetic preference changes with the degree of the visceral positive value against which the pleasurable felt quality of the aesthetic of an aesthetic preference emerges and is subjectively felt. It is the bodily and embodied signal of aesthetic preference constitution.

As I have stressed above, the locus of this visceral cognitive-emotional viable value is the subjectively aroused lived body. Taking the enactive role of the cognitive-emotional aroused lived body into account, we can say that the experience of the temporary and relative feeling of wholeness of an aesthetic preference can emerge only when its cognitive-emotional 
bodily conditions are reflectively experienced through the cognitive-emotional aroused lived body.

Such a reflective experience relates in a cognitive-emotional way the subjectively lived body to itself and to the enacted phenomenal world in the organism-environment transaction. In other words, the cognitive-emotional sense-making of the lived body brings forth viable degrees of value creating the visceral conditions for experiencing the felt quality of an aesthetic preference while bringing it forth in enacting a phenomenal world.

\section{Summary and Conclusion}

The aim of this paper has been to bring aesthetic preference research closer to the enactive approach to human experience, rejecting the mind/ body dichotomy that characterizes mainstream aesthetic preference research.

Mark Johnson's view that aesthetics is the study of the human capacity to experience the bodily conditions of meaning constitution that grows from our bodily conditions of life, has been used as a starting-point to reject the pragmatist and phenomenological implausibility of disembodied stimulus-centric approaches to aesthetic preference and to introduce the role of the embodied interconnection of cognition and emotion, the continuity between mind and body and hence the cognitive-emotional role of the subjectively lived body to aesthetic preference research.

I have argued that thanks to the conscious experiential access to the pre-reflective cognitive-emotional evaluation of viable degrees of value of environmental factors, through the aroused lived body the subject can become aware of different degrees of the felt pleasurable quality of the 'aesthetic' of an aesthetic preference. Such a felt quality is temporary and relative, as it depends on the visceral viable degree of value against which the experience of the aesthetic of an aesthetic preference as a bodily mediated temporary and relative feeling of wholeness emerges and is consciously and subjectively felt.

\section{Notes}

1. Mark Johnson, The Meaning of the Body: Aesthetics of Human Understanding (Chicago: The Chicago University Press, 2007), 218.

2. Ibd., 217-218.

3. Richard Shusterman, Pragmatist Aesthetics: Living Beauty, Rethinking Art (Oxford: Blackwell, 1992), 6.

4. The view that aesthetics is a source of pre-linguistic knowledge has been 
supported in aesthetic research in the field of empirical aesthetics in Allan Whitfield, "Aesthetics as pre-linguistic knowledge: a psychological perspective", Design Issues 21, no. 1 (2009): 3-17. Whitfield looks at aesthetics as a pre-linguistic cognitive stage of human evolution. Even if he develops his claim following the mind/body dichotomy, his view of aesthetics is close to Johnson's claim that the aesthetic is pre-linguistic sensory-perceptual meaning. While Mark Johnson focuses on the embodied meaning constitution rejecting the Cartesian dualism, Whitfield follows the idea of a dualistic interplay of emotion, cognition and perception based on representationalism. He argues that the function of aesthetics is to elaborate the categories by which we understand the world by attaching emotion to sensory perception and cognition. In formulating his claim he draws upon the emotional response category theory developed in Paula Niedenthal and Nathalie Dalle, "Le mariage de mon meilleur ami: emotional response. Categorization and naturally induced emotions", European Journal of Social Psychology 31 (2001): 737-42. According to this study, emotional states provide a type of conceptual coherence such that objects and events that elicit the same emotion are grouped together into categories and treated as the same sort of things.

5. Cf. Johnson, The Meaning of the Body, 212-13.

6. Cf. Shusterman, Pragmatist Aesthetics, 10.

7. Cf. Johnson, The Meaning of the Body, 117-18.

8.Cf. Francisco Varela, Evan Thompson, and Eleanor Rosch, The Embodied Mind: Cognitive Science and Human Experience (Cambridge, Mass.: The MIT Press, 1991); Evan Thompson, Mind in Life: Biology, Phenomenology, and the Sciences of the Mind (Cambridge, Mass.: Harvard University Press, 2007).

9. Cf. Johnson, The Meaning of the Body; Giovanna Colombetti, "Enaction, sense-making and emotion", in Enaction: Toward a New Paradigm for Cognitive Science, eds. John Stewart, Olivier Gapenne, and Ezequiel Di Paolo (Cambridge, Mass.: MIT Press, 2010), 145 - 164; Giovanna Colombetti, "Enactive appraisal", Phenomenology and the Cognitive Sciences 6 (2007): 527-46.

10. Cf. Ezequiel Di Paolo, "Autopoiesis, adaptivity, teleology, agency", Phenomenology and the Cognitive Sciences 4 (2005): 429-52 and Giovanna Colombetti, "Enaction, sense-making and emotion".

11. Daniel Berlyne, "Complexity and incongruity variables as determinants of exploratory choice and evaluative ratings", Canadian Journal of Psychology 17 (1963): 274-90; Daniel Berlyne, Aesthetics and Psychobiology (New York: Appleton-Century Crofts, 1971); Colin Martindale and Kethleen Moore, "Priming, Prototypicality, Preferences", Journal of Experimental Psychology: Human Perception and Performance 14, no. 4 (1988): 661-70; Colin Martindale, Kathleen Moore, and Jonathan Borkum, "Aesthetic preference: anomalous findings for Berlyne's psychobiological theory", American Journal of Psychology 103, no. 1 
(1990): 53-80; Paul Hekkert, Dirk Snelders, and Piet van Wieringen, “Most advanced, yet acceptable': typicality and novelty as joint predictors of aesthetic preference in industrial design", British Journal of Psychology 94 (2003): 111-24; Allan Whitfield, "Predicting preference for familiar, everyday objects: an experimental confrontation between two theories of aesthetic behavior", Journal of Environmental Psychology 3, no. 3 (1983): 221-37; Allan Whitfield, "Beyond prototypicality: toward a categorical-motivational model of aesthetics", Empirical Studies of the Arts 18, no. 1 (2000): 1-11; Paul Silvia, "Emotional responses to art. From collation and arousal to cognition and emotion", Review of General Psychology 9, no. 4 (2005): 342-57.

12. Cf. Mark Browne, and Ellen Dissanayake, "The arts are more than aesthetics: neuroaesthetics as narrow aesthetics", in Neuroaesthetics, eds. Martin Skov and Oshin Vartanian (Amityville, N.Y.: Baywood, 2009), 43-57.

13. Cf. Martindale and Moore, "Priming, Prototypicality, Preferences".

14. Cf. Colombetti, "Enaction, sense-making and emotion".

15. According to traditional emotion theories, the notion of emotion is constituted simultaneously by a mental and a bodily event. The mental side of an emotion is called appraisal and the bodily side is called arousal. Without a cognitive activity there can be no emotion, there can be just bodily arousal.

16. Maurice Merleau-Ponty, The Structure of Behaviour (Boston: Beacon Press, 1963).

17. Cf. Daniel Berlyne, "Complexity and incongruity variables as determinants of exploratory choice and evaluative ratings" and Daniel Berlyne, "Aesthetics and Psychobiology".

18. For a description of behaviorism as a disembodied approach see Francisco Varela, and Evan Thompson, and Eleanor Rosch, The Embodied Mind: Cognitive Science and Human Experience, 44-45.

19. Cf. Silvia, "Emotional responses to art. From collation and arousal to cognition and emotion".

20. Cf. Daniel Berlyne, Aesthetics and Psychobiology, 69.

21. Cf. Silvia, "Emotional responses to art. From collation and arousal to cognition and emotion" and Colombetti, "Enaction, sense-making and emotion".

22. Cf. Martindale and Moore, "Priming, prototypicality, preferences" and Martindale, Moore and Borkum, "Aesthetic preference: anomalous findings for Berlyne's psychobiological theory".

23. Adrian North, and David Hargreaves, "Collative variables versus prototypicality", Empirical Studies of the Arts 18, no. 1 (2000): 13-17.

24. Paul Hekkert, Dirk Snelders, and Piet van Wieringen, "Most advanced, yet acceptable: typicality and novelty as joint predictors of aesthetic preference in industrial design". 
25. In the study by Hekkert and colleagues the notion of familiarity and the notion of typicality are used in the same sense as prototypicality.

26. See Johnson, The Meaning of the Body, 140, 121.

27. Cf. Johnson, op. cit., 26-27; 74-75; 131; Thompson, Mind in Life, 246-48.

28. Claire Petitmengin, "Towards the Source of Thoughts: The Gestural and Transmodal Dimension of Lived Experience", Journal of Consciousness Studies 17, no. 4 (2007): 54-82; Claire Petitmengin and Michel Bitbol, "The Validity of First-Person Descriptions as Authenticity and Coherence", Journal of Consciousness Studies 16, no. 10-12 (2009): 363-404.

29. Johnson op. cit., 31, 41.

30. Thompson, op. cit., 250.

31. Les Todres and Kathleen Galvin, "Embodied interpretation: a novel way of evocatively re-presenting meanings in phenomenological research", Qualitative Research 8, no. 5 (2008): 568-83.

32. The difference between lived body and living body is illustrated by Evan Thompson, op. cit., p. 236-38.

33. Cf. Evan Thompson, op. cit., p. 237.

34. Cf. Di Paolo, "Autopoiesis, adaptivity, teleology, agency" and Colombetti, "Enaction, sense-making and emotion".

35. Di Paolo, op. cit., 440.

36. Cf. Colombetti, op. cit.

37. Cf. Di Paolo, op. cit. and Colombetti, op. cit.

38. See Colombetti, op. cit.

39. Cf. Johnson, The Meaning of the Body, 25.

40. Cf. Johnson, op. cit.

41. Cf. Colombetti, "Enactive appraisal" and "Enaction, sense-making and emotion".

42. Cf. Colombetti, "Enaction, sense-making and emotion".

43. Cf. Colombetti, "Enactive appraisal" and "Enaction, sense-making and emotion".

44. See Thompson, Mind in Life, 250-52.

45. Cf. Colombetti, "Enaction, sense-making and emotion".

46. Cf. John Dewey, Art as Experience (New York: Minton, Balch, 1934).

47. Shusterman, Pragmatist Aesthetics, 33. 